University of Nebraska - Lincoln

DigitalCommons@University of Nebraska - Lincoln

Publications from USDA-ARS / UNL Faculty

U.S. Department of Agriculture: Agricultural

Research Service, Lincoln, Nebraska

2012

Development of an environmentally friendly halogen-free phosphorus-nitrogen bond flame retardant for cotton fabrics

\author{
Thach-Mien D. Nguyen \\ USDA-ARS, Thach-mien.Nguyen@ars.usda.gov \\ SeChin Chang \\ USDA-ARS, sechin.chang@ars.usda.gov \\ Brian Condon \\ USDA-ARS, Brian.Condon@ars.usda.gov \\ Minori Uchimiya \\ USDA-ARS, sophie.uchimiya@ars.usda.gov \\ Chanel Fortier \\ USDA-ARS, Chanel.Fortier@ars.usda.gov
}

Follow this and additional works at: https://digitalcommons.unl.edu/usdaarsfacpub

Nguyen, Thach-Mien D.; Chang, SeChin; Condon, Brian; Uchimiya, Minori; and Fortier, Chanel, "Development of an environmentally friendly halogen-free phosphorus-nitrogen bond flame retardant for cotton fabrics" (2012). Publications from USDA-ARS / UNL Faculty. 1115.

https://digitalcommons.unl.edu/usdaarsfacpub/1115

This Article is brought to you for free and open access by the U.S. Department of Agriculture: Agricultural Research Service, Lincoln, Nebraska at DigitalCommons@University of Nebraska - Lincoln. It has been accepted for inclusion in Publications from USDA-ARS / UNL Faculty by an authorized administrator of DigitalCommons@University of Nebraska - Lincoln. 


\title{
Development of an environmentally friendly halogen-free phosphorus-nitrogen bond flame retardant for cotton fabrics
}

\author{
Thach-Mien D. Nguyen, SeChin Chang*, Brian Condon, \\ Minori Uchimiya and Chanel Fortier
}

\begin{abstract}
A novel flame retardant diethyl 4-methylpiperazin-1-ylphosphoramidate ( $\mathrm{CN}-3)$ containing phosphorous and nitrogen was prepared. Its chemical structure was confirmed by nuclear magnetic resonance $\left({ }^{1} \mathrm{H}-,{ }^{13} \mathrm{C}-\right.$, and $\left.{ }^{31} \mathrm{P}-\mathrm{NMR}\right)$, Fourier transform infrared spectroscopy, and elemental analysis. Print cloth and twill fabrics were treated with CN-3 to achieve different levels of add-on (7-22 wt\% add-ons for print cloth and 3-18 wt\% add-ons for twill). Thermogravimetric analysis, vertical flame test, and limiting oxygen index (LOI) were performed on the treated cotton fabrics and showed promising results. When the treated print cloth and twill fabric samples were tested using the vertical flame test (ASTM D6413-08), we observed that the ignited fabrics self-extinguished and left behind a streak of char. Treated higher add-ons fabrics were neither consumed by flame nor produced glowing ambers upon selfextinguishing. LOI (ASTM 2863-09) was used to determine the effectiveness of the flame retardant on the treated fabrics. LOI values increased from 18 vol\% oxygen in nitrogen for untreated print cloth and twill fabrics to maximum of $\mathbf{2 8}$ and $31 \mathrm{wt} \%$ for the highest add-ons of print cloth and twill, respectively. The results from cotton fabrics treated with CN-3 demonstrated a higher LOI value as well as a higher char yield because of the effectiveness of phosphorus and nitrogen as a flame retardant for cotton fabrics. Furthermore, FT-IR and SEM were used to characterize the chemical structure on the treated fabrics as well as the surface morphology of char areas of treated and untreated fabrics. Published 2012. This article is a US Government work and is in the public domain in the USA.
\end{abstract}

Keywords: cotton; flame retardant; phosphoramidate; flammability test; thermal degradation

\section{INTRODUCTION}

In reviewing the history of flame retardants (FRs), most treatments, chemical formulations, and additives were derived from chemistry developed in the 1950 s to 1980 s. $^{[1]}$ Since this time, increasing concerns over the toxicological and environmental consequences of using these chemicals on textile surfaces and in close contact with the skin have brought into attention the development and applications of new chemistry by both research scientists and industry. In the past 20 years, many workers have launched into research that enhances FR performance at an inexpensive cost and improves efficiency. This was performed by replacing areas of concern with other existing formulations or by using known chemistry in novel ways.

During their development, nitrogen and nitrogen-phosphorous compounds have been known to evolve low toxic gases or vapors as well as low evolution of smoke during combustion and are better in the aspects of recyclability. ${ }^{[2]}$ Nitrogen-phosphorus compounds of this category are nitrogen containing phosphorous compounds such as melamine or ammonium phosphate. ${ }^{[3,4]} \mathrm{A}$ combination of phosphorous and nitrogen, such as phosphoric acid and urea on cotton, was found to be synergistic. ${ }^{[5]}$ The reason for the synergistic effect is that phosphorous offers the tendency of char formation, and nitrogen forms a protective char during fire. ${ }^{[6-10]}$ Basic interaction of nitrogen and phosphorous in cellulose flame retardancy has been evaluated and shows N-P synergism. ${ }^{[11,12]}$

Among nitrogen-phosphorous compounds, phosphoramidates are very promising ${ }^{[13-18]} \mathrm{FRs}$. They are cheap to manufacture, have low volatility, provide good thermal stability, and enhance char formation during the burning process. They provide better flame retardancy on cellulose than phosphates themselves. ${ }^{[14,19,20]}$ Reaction between phosphoramidates or phosphoramides and the substrates, such as cotton and wood, have been investigated by some workers. ${ }^{[13,20,21]}$

This article describes the preparation and thermal behavior of a new phosphoramidate FR for cotton print cloth and twill fabrics. Diethyl 4-methylpiperazin-1-ylphosphoramidate, 1, has been synthesized from 1-amino-4-methyl piperazine. The structure of $\mathbf{1}$ was characterized by nuclear magnetic resonance (NMR), Fourier transform infrared spectroscopy (FTIR), and elemental analysis by inductively coupled plasma (ICP). Its thermal properties and flame retardancy were investigated by thermogravimetric analysis (TGA), limiting oxygen index (LOI), and vertical flammability testing. The content of nitrogen and phosphorous was examined; meanwhile, microstructures of treated and untreated cotton print cloth and twill fabric were studied.

\footnotetext{
* Correspondence to: SeChin Chang, Cotton Chemistry and Utilization Unit, Southern Regional Research Center, USDA-ARS, 1100 Robert E. Lee Blvd., New Orleans, LA 70124, USA.

E-mail: sechin.chang@ars.usda.gov
}

Southern Regional Research Center, USDA-ARS, 1100 Robert E. Lee Blvd., New Orleans, LA, 70124, USA 


\section{EXPERIMENTAL}

\section{Materials}

Chemicals were purchased from Aldrich and used as received. Tetrahydrofuran (THF) solvent was purchased from Aldrich and was dried using a Solvent Purification System from Innovative Technology. The reaction was conducted under nitrogen atmospheric conditions and monitored using silica gel $60 \mathrm{~F}_{254}$ thin layer chromatography purchased from EMD. Print cloth fabric, $107 \mathrm{~g} / \mathrm{m}^{2}$ (Testfabrics, Inc., Style 400M), was bleached, desized, and mercerized. Twill fabric, $258 \mathrm{~g} / \mathrm{m}^{2}$ (Testfabrics, Inc., Style 423), was bleached and mercerized.

\section{Synthesis and characterization of diethyl 4-methylpiperazin- 1-ylphosphoramidate (CN-3)}

To a solution of 1-amino-4-methyl piperazine $(3.0 \mathrm{gm}, 26 \mathrm{mmol})$ in dry THF, we added triethylamine $(3.64 \mathrm{ml}, 26 \mathrm{mmol})$ in dry THF, and the mixture was cooled to $0{ }^{\circ} \mathrm{C}$. A solution of diethyl chlorophosphate in dry THF was slowly added by addition funnel to the above mixture while stirring under nitrogen. After the addition, the reaction was allowed to warm up to room temperature and monitored by TLC using $10 \% \mathrm{MeOH} /$ EtOAC as an eluent and iodine as staining reagent. When the reaction was over, a white solid was filtered off. The removal of the solvent gave a yellowish oil as product in $82 \%$ yield with no purification needed. ${ }^{1} \mathrm{H}-\mathrm{NMR}$ $\left(400 \mathrm{MHz}, \mathrm{CDCl}_{3}\right) \delta$-ppm: $1.34\left(\mathrm{t}, 6 \mathrm{H},-\mathrm{CH}_{3}\right), 2.30\left(\mathrm{~s}, 3 \mathrm{H},-\mathrm{CH}_{3}\right), 2.54$ $\left(\mathrm{s}, 4 \mathrm{H},-\mathrm{CH}_{2}-\right), 2.83\left(\mathrm{~s}, 4 \mathrm{H},-\mathrm{CH}_{2}-\right), 4.10\left(\mathrm{~m}, 4 \mathrm{H},-\mathrm{CH}_{2}-\right)$, and 4.70 (d, $\left.1 \mathrm{H},{ }^{2} \mathrm{~J}_{\mathrm{H}-\mathrm{P}}=32 \mathrm{~Hz}, \mathrm{NH}\right) .{ }^{13} \mathrm{C}-\mathrm{NMR}\left(400 \mathrm{MHz}, \mathrm{CDCl}_{3}\right) \delta$-ppm: 16.3 $\left(\mathrm{d}, \mathrm{J}_{\mathrm{C}-\mathrm{P}}=28 \mathrm{~Hz}\right), 45.5(\mathrm{~s}), 54.4(\mathrm{~s}), 57.6\left(\mathrm{~d}, \mathrm{~J}_{\mathrm{C}-\mathrm{P}}=24 \mathrm{~Hz}\right)$, and 62.8 $\left(\mathrm{d}, \mathrm{J}_{\mathrm{C}-\mathrm{P}}=24 \mathrm{~Hz}\right) .{ }^{31} \mathrm{P}-\mathrm{NMR}\left(400 \mathrm{MHz}, \mathrm{CDCl}_{3}\right) \delta$-ppm: 6.00-6.25 (m), IR $\left(\mathrm{cm}^{-1}\right)$ 959, 1026, 1143, 1159, 1231, 1459, 2794, 2937, 2977, and 3169. Anal. Calcd for $\mathrm{C}_{9} \mathrm{H}_{22} \mathrm{~N}_{3} \mathrm{O}_{3} \mathrm{P}: \mathrm{C}=43.02 \%, \mathrm{H}=8.83 \%$, $\mathrm{N}=16.72 \%, \mathrm{P}=12.33 \%$. Found $\mathrm{C}=42.18 \%, \mathrm{H}=9.23 \%, \mathrm{~N}=16.90 \%$, $\mathrm{P}=12.12 \%$.

\section{Measurements}

NMR spectra were recorded on a Varian 400-MHz instrument using $\mathrm{CDCl}_{3}$ as solvent. ${ }^{1} \mathrm{H}$ - and ${ }^{13} \mathrm{C}$-NMR are given in $\delta$ relative to TMS. ${ }^{31} \mathrm{P}$ is given in $\delta$ relative to external $85 \%$ aqueous $\mathrm{H}_{3} \mathrm{PO}_{4}$. Elemental analyses were carried out on a 2400 series II CHNS/O Analyser, PerkinElmer and ICP Leeman Labs Prodigy/ Prism at 253 and $561 \mathrm{~nm}$. FT-IR spectra were recorded in a Bruker Vertex 70 spectrometer equipped with a MIRacle ATR accessory (Pike Technologies) fitted with a diamond/ZnSe crystal plate. Samples were placed atop the crystal plate without any special preparation. A scan of the clean crystal plate was used as the background. All reported spectra were collected with a spectral resolution of $4 \mathrm{~cm}^{-1}$ and are shown as the co-addition of 64 scans. Spectra are presented without modifications. Fabric degradations were observed for treated and untreated fabrics. Vertical flame tests were performed on strips of fabric $(30 \times 7.6 \mathrm{~cm})$ according to ASTM D-6413-08. ${ }^{[22]}$ LOI tests were conducted using strips of fabric $(13 \times 6 \mathrm{~cm})$ according to ASTM D2863-09. ${ }^{[23]}$ Thermogravimetric analyses were performed using a TA Instruments Q500 under nitrogen and air conditions. Analyses were monitored between 20 and $600^{\circ} \mathrm{C}$ at a heating rate of $10^{\circ} \mathrm{C} / \mathrm{min}$ and a flow rate of $60 \mathrm{ml} / \mathrm{min}$. The onset of degradation ${ }^{[24]}$ and char contents at $600^{\circ} \mathrm{C}$ were obtained from TGA thermograms. SEM experiment was performed on Philips XL 30 ESEM with a magnification of $1500 \times$. Samples were coated with gold for analysis purposes.
Analyses were carried out on different regions of print cloth and twill fabrics: treated/unburned, treated/edge, and treated/burned.

\section{Fabric treatment}

Cotton fabrics were treated with $30 \%$ aqueous isopropanol formulations containing various percentages of diethyl 4-methylpiperazin-1-ylphosphoramidate (CN-3). Fabric samples were immersed in the treatment solution overnight for thorough wetting, then padded $(10 \mathrm{psi})$, dried $\left(100^{\circ} \mathrm{C}\right.$, for $\left.5 \mathrm{~min}\right)$, and cured in air $\left(160^{\circ} \mathrm{C}\right.$, for $\left.5 \mathrm{~min}\right)$.

\section{RESULTS AND DISCUSSION}

\section{Syntheses and structural characterization of $\mathrm{CN}-3$}

Diethyl 4-methylpiperazin-1-ylphosphoramidate (CN-3) was synthesized in one simple step in high yield of $82 \%$ (Scheme 1). Starting materials were available at low cost. There was no purification required and thus made the synthesis very accessible. No previous report on the synthesis of $\mathrm{CN}-3$ has been found. $\mathrm{CN}-3$ readily dissolved in most solvents such as $\mathrm{MeOH}$, THF, $\mathrm{CH}_{3} \mathrm{CN}$, EtOAC, $\mathrm{CHCl}_{3}, \mathrm{CH}_{2} \mathrm{Cl}_{2}$, and acetone. Figure 1 presents the ${ }^{1} \mathrm{H}$-NMR, ${ }^{13} \mathrm{C}-\mathrm{NMR}$, and ${ }^{31} \mathrm{P}-\mathrm{NMR}$ of $\mathrm{CN}-3 .{ }^{1} \mathrm{H},{ }^{13} \mathrm{C},{ }^{15} \mathrm{~N}$, and ${ }^{31} \mathrm{P}$ all have the same spin quantum number $I=1 / 2$, which gives rise to coupling interactions that split ${ }^{1} \mathrm{H}-{ }^{31} \mathrm{P},{ }^{13} \mathrm{C}-{ }^{31} \mathrm{P}$, and ${ }^{15} \mathrm{~N}-{ }^{31} \mathrm{P}$ resonances by the $2 n /+1$ rule. This explains the doublet patterns in all proton, carbon, and phosphorous spectra. In ${ }^{1} \mathrm{H}-\mathrm{NMR}$, the doublet at $4.70 \mathrm{ppm}$ with $J=32 \mathrm{~Hz}$ corresponds to the two-bond $\mathrm{P}-\mathrm{H}$ coupling constant of $\mathrm{NH}$ proton. ${ }^{[25]}$ The multiplet at $4.10 \mathrm{ppm}$ is attributed to the $-\mathrm{CH}_{2}-$ of the phosphate group because these protons not only couple with $-\mathrm{CH}_{3}$ proton but also couple with phosphorous. Two singlets at 2.83 and $2.54 \mathrm{ppm}$ are protons of the piperazine ring. One singlet at $2.30 \mathrm{ppm}$ corresponds to $-\mathrm{CH}_{3}$ of the piperazine ring. A triplet at $1.34 \mathrm{ppm}$ is due to the $-\mathrm{CH}_{3}$ of the phosphate group. The ${ }^{13} \mathrm{C}$ presents two doublet resonances at $15.9 \mathrm{ppm}(J=27.2 \mathrm{~Hz})$ and $62.8 \mathrm{ppm}(24.4 \mathrm{~Hz})$ belonging to carbons of the phosphate group (based on the ${ }^{13} \mathrm{C}-\mathrm{NMR}$ of phosphate reagent). One doublet at $57.3 \mathrm{ppm}(J=21.2 \mathrm{~Hz})$ is carbon from $\mathrm{NH}-\mathrm{N}-\mathrm{C}$. The resonance of phosphorous is in a form of two multiplets resulting from the heteronuclear coupling between ${ }^{31} \mathrm{P}$ and ${ }^{15} \mathrm{~N}$ nuclei and then ${ }^{31} \mathrm{P}$ and ${ }^{1} \mathrm{H}$ and ${ }^{31} \mathrm{P}$ and ${ }^{13} \mathrm{C}^{[26]}$

In Fig. 2, the FTIR data of $\mathrm{CN}-3$ (top) show the absorption of $\mathrm{NH}$ at $3169 \mathrm{~cm}^{-1}$, which is very much the same position as in normal amines. The $\mathrm{NH}$ stretching and deformation vibrations are barely affected by the presence of the phosphorous atom. ${ }^{[27]}$ The absorption band of saturated carbon $\left(\mathrm{sp}^{3}\right)$ is observed at 2977 to $2936 \mathrm{~cm}^{-1}$. ${ }^{[28]}$ The stretch at 2794 and $1378 \mathrm{~cm}^{-1}$ corresponds to the vibration of tertiary nitrogen of $\mathrm{NCH}_{3}$, and the deformation vibration of the methyl group attached to nitrogen, respectively. ${ }^{[29]}$ The absorption band of the secondary amine is seen at $1459 \mathrm{~cm}^{-1} \cdot \mathrm{P}=\mathrm{O}$ stretches show at $1231,1159 \mathrm{~m}$ and $1142 \mathrm{~cm}^{-1}$. The first absorption represents $\mathrm{P}=\mathrm{O}$ frequency with two $\mathrm{O}$-Alkyl groups and NHR group attached. ${ }^{[30]}$ The next two absorptions can be contributed to the stretching bands of hydrogen bonding between $\mathrm{P}=\mathrm{O}$ and neighboring $\mathrm{NH}^{[27]}$ The $\mathrm{P}-\mathrm{O}-$-ethyl vibrations fall in the normal range, $1026-959 \mathrm{~cm}^{-1}$, as extremely strong absorption. ${ }^{[27,31,32]}$ In addition, the absorption at $790 \mathrm{~cm}^{-1}$ corresponds to the $\mathrm{P}-\mathrm{N}$ single-bond vibration arising from the perturbation of $-\mathrm{N}-(\mathrm{C})_{2}$ attached to the nitrogen atom of $\mathrm{NH}^{[33]}$ 



CN-3

Scheme 1. Synthesis of diethyl 4-methylpiperazin-1-ylphosphoramidate (CN-3).
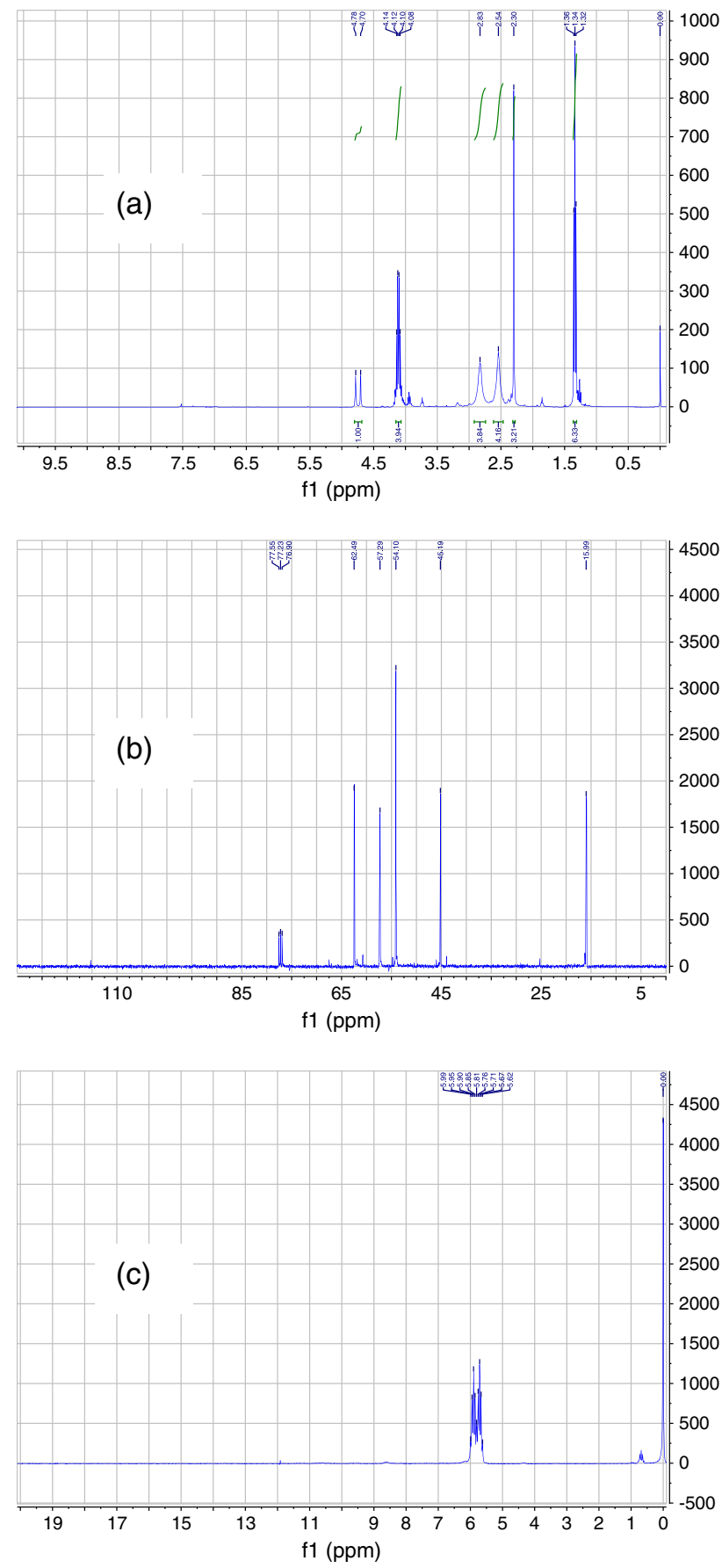

Figure 1. ${ }^{1} \mathrm{H}-,{ }^{13} \mathrm{C}$-, and ${ }^{31} \mathrm{P}-\mathrm{NMR}$ spectra of diethyl 4-methylpiperazin-1ylphosphoramidate (CN-3): (a) ${ }^{1} \mathrm{H}-\mathrm{NMR}$, (b) ${ }^{13} \mathrm{C}-\mathrm{NMR}$, and (c) ${ }^{31} \mathrm{P}-\mathrm{NMR}$ (close-up). This figure is available in colour online at wileyonlinelibrary.com/journal/pat

\section{Fabric treatment}

Cotton twill and print cloth fabrics were treated with solutions of $\mathrm{CN}-3$ ( $\mathrm{w} / \mathrm{v}$ in $30 \%$ aqueous isopropanol) at room temperature. The add-on values are summarized in Table 1. At this point, no attempt was made to test the durability of the FR with multiple laundering tests. ${ }^{[34]}$ After application, drying, and curing, the treated samples appeared white. Samples of $22 \%$ print cloth and $18 \%$ twill were washed by stirring in $40^{\circ} \mathrm{C}$ water for 10 min and then dried and cured. The original add-ons in both were reduced to $83 \%$ to $84 \%$ after the first wash and remained the same after the third wash.

FTIRs of CN-3 and control and treated print cloth and twill fabrics are presented in Fig. 2. The treated fabrics show the absorption of $\mathrm{P}=\mathrm{O}$ with $(\mathrm{O}-\mathrm{alkyl})_{2}$ and $\mathrm{NHR}$ attached at $1231 \mathrm{~cm}^{-1}$ and $\mathrm{P}-\mathrm{N}$ with perturbation effect at $790 \mathrm{~cm}^{-1}$. These stretches are observed originally in $\mathrm{CN}-3$.

The content of nitrogen and phosphorous was determined analytically for each add-on sample with three observations for nitrogen and six observations for phosphorous. The results were summarized in Table 2 and presented graphically in Fig. 3. It is apparent that the content of phosphorous and nitrogen increases with the increase of add-on value, and nitrogen content is always higher than phosphorous content in each sample. Nitrogen has been recognized to play a role in fire retardancy and adding nitrogen often reduces the need for phosphorous. ${ }^{[35]}$ The graphical $\mathrm{P}-\mathrm{N}$ synergistic effect for a variety of phosphorusnitrogen systems on cotton twill showed that $\mathrm{P}+\mathrm{N}$ should be $3.5 \%$ to $6 \%$ for flame retardancy. ${ }^{[12,36]}$ Table 2 shows that this combination was achieved at 8,13 , and $18 \mathrm{wt} \%$ add-on in treated twill and at 16 and $22 \mathrm{wt} \%$ add-on in treated print cloth.

\section{Thermal properties of treated fabric}

The thermal degradation data were obtained in a nitrogen atmosphere. Values of char content ( $\%$ at $600^{\circ} \mathrm{C}$ ) for compound $\mathrm{CN}-3$, untreated and treated twill, and print cloth fabric samples at different add-ons are listed in Table 3.

Untreated print cloth fabric degraded at $323^{\circ} \mathrm{C}$ and showed a char residue of $3 \%$ of the original weight at $600^{\circ} \mathrm{C}$. When print cloth treated with $\mathrm{CN}-3$ at $7-22 \mathrm{wt} \%$ add-on were degraded, they showed onsets of degradation between 132 and $263^{\circ} \mathrm{C}$ and provided char yields between $18 \%$ and $23 \%$. The comparison of print cloth samples and compound $\mathrm{CN}-3$ degradation by TGA is depicted in Fig. 4a. Untreated twill fabric showed an onset temperature at $327^{\circ} \mathrm{C}$ and char residue of $2 \%$ of the original weight at $600^{\circ} \mathrm{C}$. Treated twill with $\mathrm{CN}-3$ at $3-18 \mathrm{wt} \%$ add-ons were degraded between 138 and $266^{\circ} \mathrm{C}$ and provided char yield between $19 \%$ and $22 \%$. Degradation of twill samples and compound $\mathrm{CN}-3$ is presented graphically in Fig. 4b. It is apparent that the rapid degradation of $\mathrm{CN}-3$ occurs earlier at $153^{\circ} \mathrm{C}$ and later at $429^{\circ} \mathrm{C}$, and char yield was $4 \%$ at $600^{\circ} \mathrm{C}$ compared with untreated and treated fabric samples. The char percentage appears to be higher in high add-on ( $22 \mathrm{wt} \%$ print cloth and 


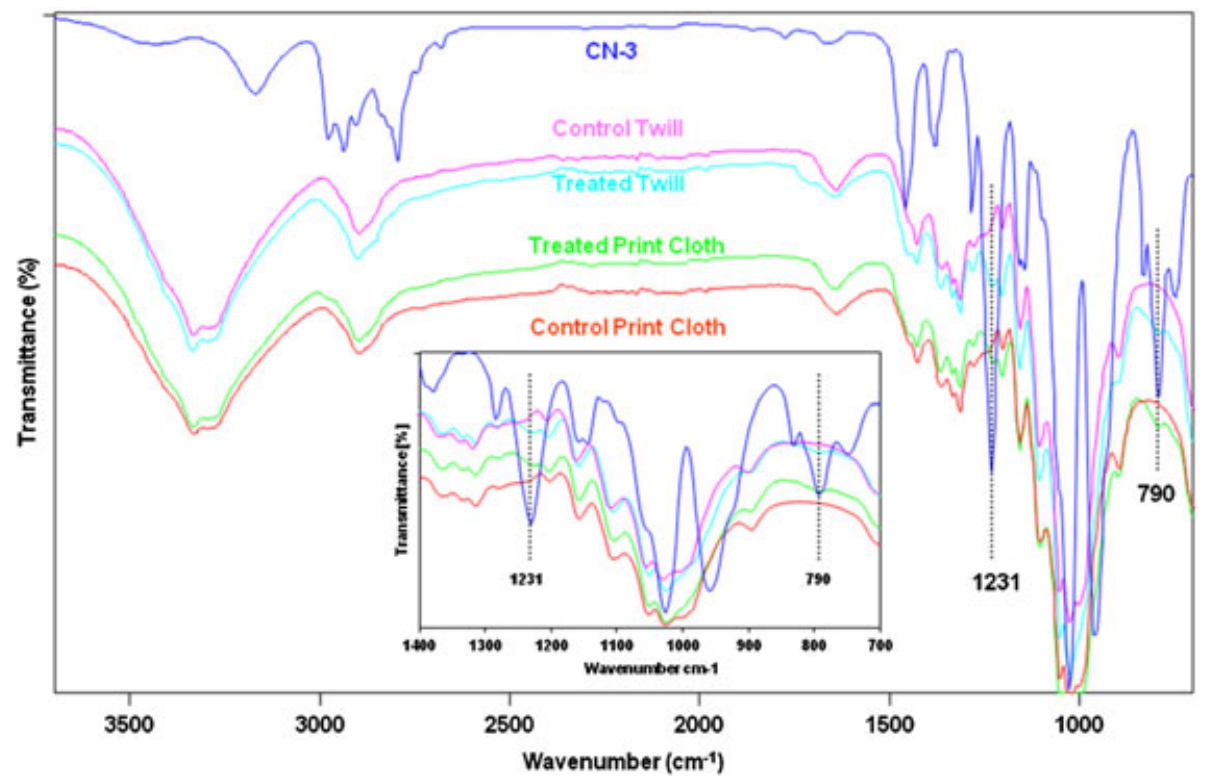

Figure 2. FTIR of diethyl 4-methylpiperazin-1-ylphosphoramidate (CN-3), control and treated (18 wt $\%)$ twill, and control and treated (22 wt $\%)$ print cloth. This figure is available in colour online at wileyonlinelibrary.com/journal/pat

Table 1. Add-ons (wt\%) after cure of treated twill and print cloth fabrics with $\mathrm{CN}-3$

\begin{tabular}{|lcc|} 
Samples numbers & $\begin{array}{c}\text { Twill add-on } \\
\text { (wt\%) }\end{array}$ & $\begin{array}{c}\text { Print cloth add-on } \\
\text { (wt\%) }\end{array}$ \\
\hline 1 & 3 & 7 \\
2 & 8 & 10 \\
3 & 13 & 16 \\
4 & 18 & 22 \\
\hline
\end{tabular}

Table 2. Content of nitrogen (average of three trials) and phosphorous (average of six trials) in treated twill and print cloth fabrics

\begin{tabular}{|c|c|c|c|c|c|c|c|}
\hline \multicolumn{4}{|c|}{ Twill } & \multicolumn{4}{|c|}{ Print cloth } \\
\hline $\begin{array}{l}\text { Add-on } \\
\text { (wt\%) }\end{array}$ & $\% \mathrm{~N}$ & $\% \mathrm{P}$ & $\% N+\% P$ & $\begin{array}{c}\text { Add-on } \\
\text { (wt\%) }\end{array}$ & $\% \mathrm{~N}$ & $\% \mathrm{P}$ & $\% N+\% P$ \\
\hline 3 & 1.25 & 0.90 & 2.15 & 7 & 1.44 & 1.16 & 2.60 \\
\hline 8 & 2.00 & 1.50 & 3.50 & 10 & 1.55 & 1.22 & 2.77 \\
\hline 13 & 2.04 & 1.74 & 3.78 & 16 & 2.03 & 1.73 & 3.76 \\
\hline 18 & 3.25 & 2.70 & 5.95 & 22 & 2.27 & 2.10 & 4.37 \\
\hline
\end{tabular}

18 wt $\%$ twill) samples than in low ones (7wt $\%$ print cloth and 3 wt $\%$ twill) and untreated samples. Between treated samples of the same or different fabric types, the changes in char residue are not significant.

As shown in Table 3, the low add-on samples of print cloth ( 7 and $10 \mathrm{wt} \%$ ) and twill ( 3 and $8 \mathrm{wt} \%$ ) have onset of degradation close to the onset of degradation of untreated ones $\left(323^{\circ} \mathrm{C}\right.$ for untreated print cloth and $327^{\circ} \mathrm{C}$ for untreated twill). When $\mathrm{CN}-3$ presents in a sufficient amount (16 and $22 \mathrm{wt} \%$ for print cloth and 13 and $18 \mathrm{wt} \%$ for twill) to act as an FR, the treated fabrics appear to have two onsets of degradation. Their first onset

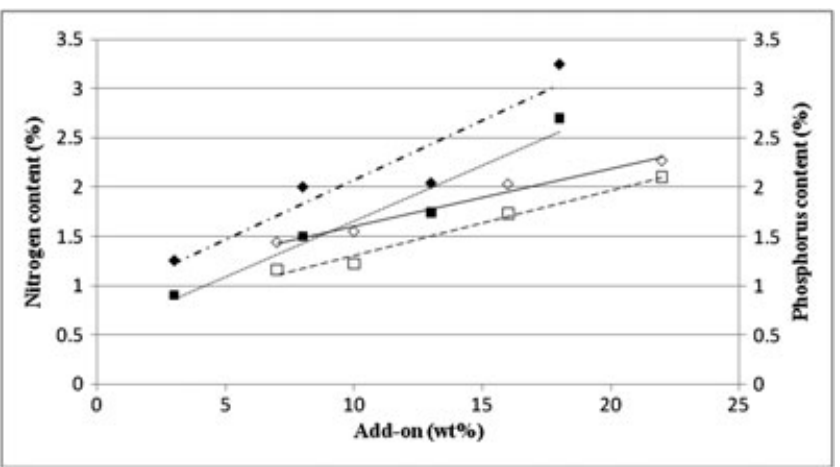

Figure 3. Content of phosphorous and nitrogen in treated fabrics: $\% \mathrm{~N}$ in twill $(\diamond), \% \mathrm{P}$ in twill $(\square), \% \mathrm{~N}$ in print cloth $(\diamond)$, and \%P in print cloth $(\square)$.

Table 3. Degradation and char content determination of $\mathrm{CN}-3$ and different add-ons (wt\%) of treated print cloth and twill fabrics by $\mathrm{TGA}$ at $600^{\circ} \mathrm{C}$ in nitrogen atmosphere (two observations for each sample)

\begin{tabular}{llrc|} 
Samples & & $\begin{array}{c}\text { Onset of } \\
\text { degradation }\left({ }^{\circ} \mathrm{C}\right)\end{array}$ & $\begin{array}{c}\text { Char at } \\
600^{\circ} \mathrm{C}(\%)\end{array}$ \\
\hline CN-3 & & 153,429 & 4 \\
Print cloth (add-on, wt\%) & 0 & 323 & 3 \\
& 7 & 263 & 18 \\
& 10 & 258 & 19 \\
& 16 & 151,251 & 20 \\
Twill (add-on, wt\%) & 22 & 132,238 & 23 \\
& 0 & 327 & 2 \\
& 3 & 266 & 19 \\
& 8 & 259 & 21 \\
& 13 & 148,253 & 22 \\
& 18 & 138,252 & 22 \\
\hline
\end{tabular}


a)

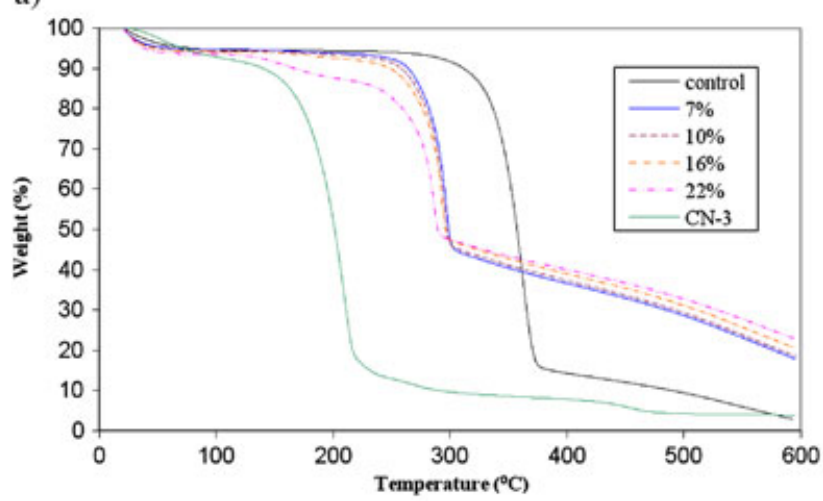

b)



Figure 4. Degradation thermograms of compound $\mathrm{CN}-3$, control, and treated fabrics at various wt $\%$ add-ons for (a) print cloth and (b) twill. This figure is available in colour online at wileyonlinelibrary.com/journal/pat

temperature is close to the first onset of degradation of $\mathrm{CN}-3$, and their second onset of degradation is close to the onset of degradation of the lower add-ons and untreated samples. Generally, the FR is expected to decompose before or near the decomposition temperature of the substrate to interfere with the burning process. ${ }^{[37]}$ Because the first thermal decomposition temperature of $\mathrm{CN}-3$ $\left(153^{\circ} \mathrm{C}\right)$ is lower than those of untreated twill and print cloth fabrics, CN-3 decomposes before the untreated fabrics and suppresses the burning process of the fabrics. This might be the explanation of two onsets of degradation in high add-on samples and how close they are to the onsets of degradation of $\mathrm{CN}-3$ as well as the low add-on samples. It is known that FRs increase the rate of decomposition and lower the decomposition temperature. ${ }^{[38]}$ In the case of phosphorous-containing FRs, FRs can reduce cellulose inflammability, primarily by dehydration, phosphorylation, and phosphate-ester decomposition mechanism. This can inhibit the release of volatile combustible fragments, enhance char formation, and therefore lower the onset of degradation. ${ }^{[37]}$ The inverse relationship of the applied amount of FRs and the decomposition temperature is also observed in the treatment of fabrics with $\mathrm{CN}-3$ and is presented in Fig. 5.

\section{Flame retardant performance}

To evaluate the FR properties of $\mathrm{CN}-3$, we investigated two important parameters: vertical flammability and LOI. Vertical flammability test results in Table 4 and Fig. 6 show the effectiveness of CN-3 as an FR when applied on twill and print cloth fabrics at add-on levels of 13,18 , and $22 \mathrm{wt} \%$, respectively. Twill fabric shows flame retardancy at lower add-on compared with print



Figure 5. Onset of degradation versus add-on value in twill ( $\downarrow)$ and print cloth (घ). For higher add-ons, first onset temperature was selected.

cloth. There are many factors that influence the add-on on fabrics. They include the type of fiber (cotton, Lycra, embroidery, etc.), the type of fabric (woven, knitted, nonwoven), the structure of fabric (plain, weave, twill, satin, etc.), the construction of fabric (weight of fabric per unit area), and the treatment conditions (in dipping, drying, curing, etc.). Print cloth and twill samples in this experiment were cotton, and they were treated in the same way. The possible cause for different add-on can be the construction of fabric. As mentioned in the Materials section, the weight per unit in print cloth was much lighter than that in twill. As the result, there is more space for air or oxygen to occupy in print cloth. Therefore, print cloth needs to pick up more $\mathrm{CN}-3$ to become FR.

There was no after-flame or after-glow for all three samples. Char lengths were $2.0-2.5 \mathrm{~cm}$ for $18 \mathrm{wt} \%$ and $2.5-4.0 \mathrm{~cm}$ for $13 \mathrm{wt} \%$ of twill and $4.0-5.0 \mathrm{~cm}$ for $22 \mathrm{wt} \%$ add-on of print cloth. Samples with 3 and $8 w t \%$ add-ons of twill had after-flame burning of less than $20 \mathrm{sec}$ with the char length more than $30 \mathrm{~cm}$ and no after-glow. The 10 and 16 wt $\%$ add-on samples of print cloth also had the char length more than $30 \mathrm{~cm}$ and no after-glow but less than $10 \mathrm{sec}$ of after-flame burning time. The $7 \mathrm{wt} \%$ add-on sample of print cloth did not have both after-flame and afterglow and the char length was also more than $30 \mathrm{~cm}$.

The flame retardancy of $\mathrm{CN}-3$ is further supported by average LOI results. As shown in Table 4, the amounts of oxygen required to burn to the $5-\mathrm{cm}$ line were 31 vol\% for $18 \mathrm{wt} \%$ add-on and 29 vol $\%$ for 13 wt $\%$ add-on of twill and 28 vol\% for $22 \mathrm{wt} \%$ addon of print cloth. The required time to burn to the $5-\mathrm{cm}$ line ranged from $41 \pm 5$ to $44 \pm 6 \mathrm{sec}$ for twill samples and $20 \pm 3 \mathrm{sec}$ for print cloth sample. Because air is composed of approximately $21 \mathrm{vol} \%$ oxygen by volume, any material with an LOI of less than 21 will burn easier in air. Materials that rank in the 21 to 27.9 vol\% range are known as slow burning. Above this range, materials are considered to be self-extinguishing. ${ }^{[39]}$ For 3 and 8 wt $\%$ add-on of twill and 7 and $10 \mathrm{wt} \%$ add-on of print cloth, LOI test showed that the $5-\mathrm{cm}$ line burned within $50 \pm 5$ to $63 \pm 2 \mathrm{sec}$ and $24 \pm 2$ to $27 \pm 2 \mathrm{sec}$ when 24 to $27 \mathrm{vol} \%$ and 23 to 25 vol\% oxygen were supplied, respectively. On the basis of vertical flammability and $\mathrm{LOI}$ results, it can be concluded that $\mathrm{CN}-3$ acts as a good FR when applied on cotton twill and print cloth fabrics at the level of 13 to 18 and $22 \mathrm{wt} \%$ add-ons, respectively.

From the results of thermal degradation and LOI testing, it is obvious that the percentage of char at $600^{\circ} \mathrm{C}$ and the minimum concentration of oxygen that will support combustion of the treated fabrics increase with the increase of add-on value. This positive relationship is presented in Fig. 7. 
Table 4. Vertical flammability test (ASTM D-6413-08 ${ }^{[1]}$ and LOI test (ASTM D-2863-09) $)^{[2]}$ of treated twill and print cloth fabrics at different wt\% add-on

Add-on (wt\%) After-flame time (sec) After-glow time (sec) Char length (cm) Average LOI (\%) $[\sigma]^{\mathrm{a}}$ and time $(\mathrm{sec})$

\begin{tabular}{llcc}
\hline Twill & 3 & $14-19$ & 0 \\
& 8 & $17-18$ & 0 \\
& 13 & 0 & 0 \\
Print cloth & 7 & 0 & 0 \\
& 10 & 0 & 0 \\
& 16 & $2-4$ & 0 \\
& 22 & 0 & 0 \\
a[ $\sigma]=$ standard deviation. & & 0 \\
\\
Microstructure studies of different regions of twill and print \\
cloth fabrics
\end{tabular}

The microstructures of treated/burned, treated/edge, and control/ burned areas of twill and print cloth fabrics are presented in Fig. 8. All burned samples were collected at the area where flame contacted with the fabrics and turned the fabrics from white to black. Treated/edge sample was obtained in the region between the burned and the unburned area and appeared to be brown. All samples were obtained after vertical flammability testing.

It can be seen that compound $\mathrm{CN}-3$ acts the same on both types of fabric. The surface of treated/edge (Fig. 8A) shows material that appears to be frothy and swollen. The occurrence of the blisters (nodules) can be due to the entrapment of decomposition gases in the coating of $\mathrm{CN}-3$ on the surface. In the treated/burned area, these nodules become bigger because the high heat causes the

a)



b) Control

$3 \mathrm{wt} \%$

$8 \mathrm{wt} \%$

$13 \mathrm{wt} \%$

$18 \mathrm{wt} \%$

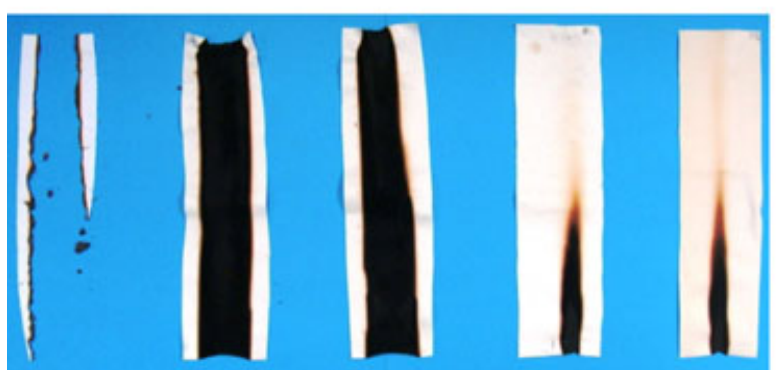

Figure 6. Vertical flammability test results of (a) control and treated print cloth fabric and (b) control and treated twill fabric (two trials for each add-on value). This figure is available in colour online at wileyon linelibrary.com/journal/pat expansion of gases (Fig. 8B). The internal pressure of these blisters continues to form and causes the explosion to release the built-up gases as seen in Fig. 8C, the low-magnification image of Fig. 8B. As seen in Figs $8 B$ and $8 C$, the structure of cotton is not destroyed when the fabric is being burned.

The untreated fabrics are completely burned up in the air when flame is applied (Fig. 8D). The outer surface of its residue is more threadlike because during ignition, the cotton component is the initial and only source of fuel, which is first decomposed and caught fire and subsequently burned intensely. There are no additional chemicals or substances to cohere these threads together as seen in other case. ${ }^{[40]}$

\section{Possible mechanism of $\mathrm{CN}-3$ on cotton fabrics}

$\mathrm{CN}-3$ belongs to the phosphoramidate class. Much of the chemical interest in this class of compounds is due to the presence of the $\mathrm{P}-\mathrm{N}$ bond and its susceptibility to cleavage in aqueous acidic solution. ${ }^{[41-43]}$ Hydrolysis in alkaline solution leads principally to $\mathrm{P}-\mathrm{O}$ bond cleavage. ${ }^{[44]}$ Phosphoramidates can thermally decompose. In this case, they can be transformed to acidic intermediate via several possible reaction pathways, depending on the group attached to the nitrogen. ${ }^{[45]} \mathrm{P}-\mathrm{O}$ bond cleavage in transesterification or $\mathrm{P}-\mathrm{N}$ bond cleavage in hydrolysis is proposed depending on the environment and the substituent on the nitrogen. In the case of $\mathrm{CN}-3$, transesterification is expected to happen because the cellulose is mercerized and physically absorbed



Figure 7. Percentage of char at $600^{\circ} \mathrm{C}$ and LOl value versus add-on value in treated print cloth and twill fabrics. and $\diamond, \boldsymbol{\Delta}$ and $\Delta$ are the percentage of char and the LOI value of treated twill and print cloth, respectively. 
1) Print cloth

A



$\mathrm{C}$

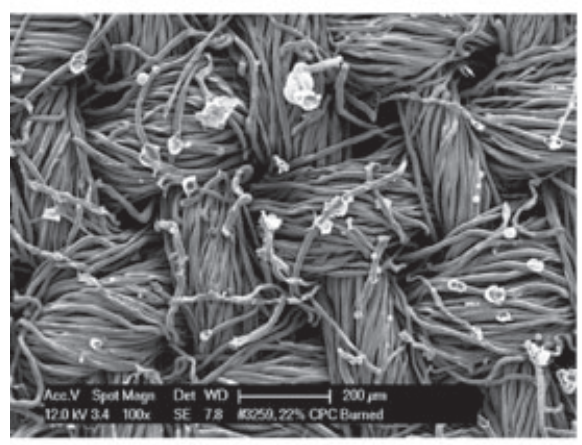

2) Twill fabric

A



C



B



$\mathrm{D}$



B

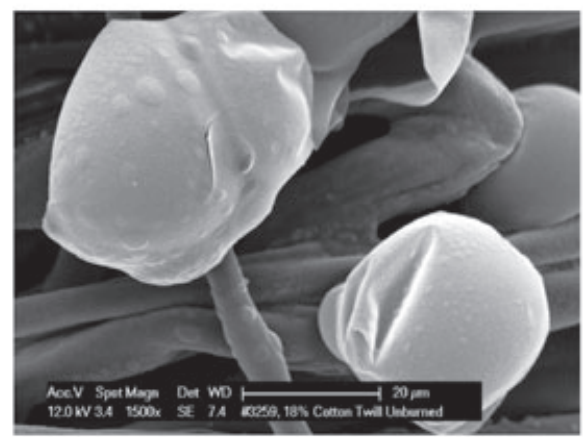

$\mathrm{D}$

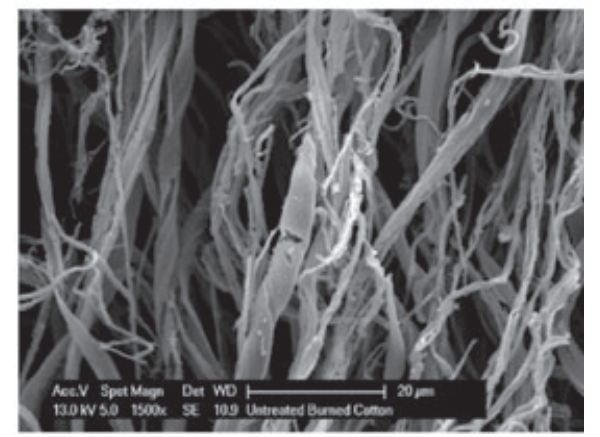

Figure 8. SEM micrographs of different regions of fabric: (1) print cloth (2) twill fabric with.

water in cotton can make the environment slightly basic to catalyze the exchange process between $\mathrm{O}-\mathrm{Cell}$ and $\mathrm{O}-\mathrm{CH}_{2} \mathrm{CH}_{3}$ at high temperature. Moreover, FTIR data of treated twill and print cloth show the absorptions at 1231 and $790 \mathrm{~cm}^{-1}$, which 


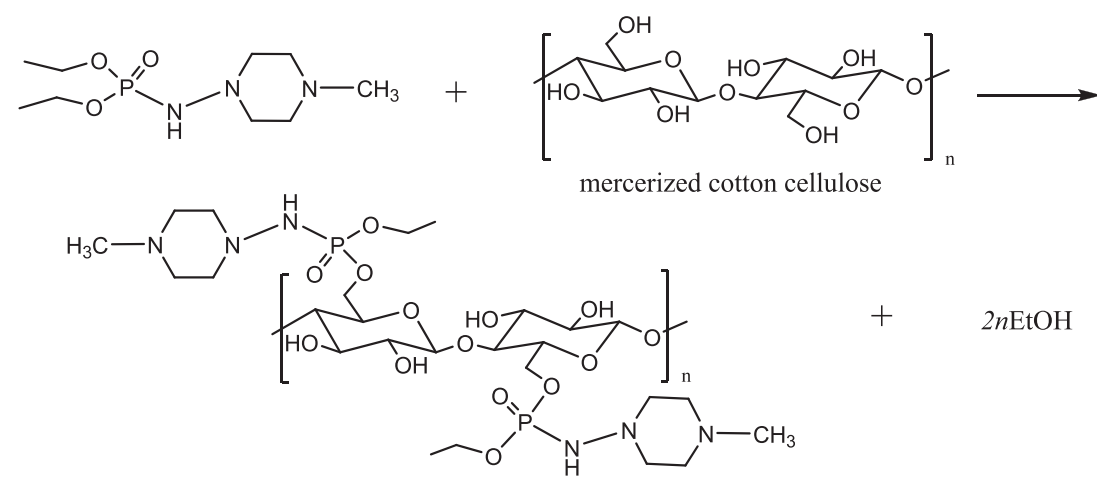

Scheme 2. Thermal decomposition of cotton cellulose treated with diethyl 4-methylpiperazin-1-ylphosphoramidate (CN-3).

represent $\mathrm{P}=\mathrm{O}$ frequency with $\mathrm{O}-\mathrm{Alkyl}$ and NHR groups attached and $\mathrm{P}-\mathrm{N}$ with perturbation effect, respectively. Scheme 2 postulates the reaction between the $\mathrm{CN}-3$ and the cotton cellulose.

\section{CONCLUSIONS}

A novel reactive $\mathrm{FR}, \mathrm{CN}-3$, for cotton twill and cotton print cloth fabrics was successfully synthesized and characterized by reacting 1-amino-4-methyl piperazine with diethyl chlorophosphate. The decomposition of $\mathrm{CN}-3$ in nitrogen by TGA occurred at $153^{\circ} \mathrm{C}$, and char yield was $4 \%$ at $600^{\circ} \mathrm{C}$.

For FR fabric treatment, twill and print cloth fabrics were soaked in a $30 \%$ aqueous isopropanol formulation at room temperature, dried at $100^{\circ} \mathrm{C}$ for $5 \mathrm{~min}$, and cured at $160^{\circ} \mathrm{C}$ for $5 \mathrm{~min}$ dwell time. After applications, treated fabrics were cured to afford add-on values of 7 to $22 \mathrm{wt} \%$ for print cloth and 3 to 18 wt $\%$ for twill fabric. TGA results showed that compound $\mathrm{CN}-3$ and the treated print cloth and twill fabrics were degraded at much lower temperatures and produced higher char yields at $600^{\circ} \mathrm{C}$ in nitrogen compared with that of untreated fabrics.

Treated fabrics exhibited FR properties in vertical flame and LOI testing. They passed the vertical flame test when add-on values were $22 \mathrm{wt} \%$ for print cloth and 13 and $18 \mathrm{wt} \%$ for twill. Their char lengths were less than $50 \%$ of the original fabric with no after-flame and after-glow times. Untreated fabric showed an LOI value of 12 vol\% for print cloth and 18 vol\% for twill, whereas treated print cloth and twill appeared to have 28 vol\% and 29 and 31 vol\% of LOI value, respectively. SEM micrographs indicated that treated fabrics could form a protective layer, which prevented the fabric from being burned completely. Further investigation to improve the durability is underway.

\section{Acknowledgements}

The authors thank the United States Department of Agriculture for financial support. They also express their gratitude to the $\mathrm{Dr}$ Ryan Slopek, Jade Smith, Elena Graves, Linda Wartelle and Christa Madison.

\section{REFERENCES}

[1] A. R. Horrocks, Rev. Prog. Color. 1986, 16, 62.

[2] H. Horacek, R. Grabner, Polym. Degrad. Stab. 1996, 54, 205.

[3] W. G. Kuryla, A. J. Papa, Flame Retardancy of Polymeric Materials, Vol. 1. Marcel Dekker Inc., New York, 1973, 134.
[4] R. B. Hindersinn, Historical aspects of polymer fire retardancy. In: Fire and Polymers, Hazards Identification and Prvention, Chap 7, ACS Symposium Series, 1989, 425.

[5] J. M. Church, R. W. Little, A. Coppick, Ind. Eng. Chem. 1950, 42, 41.

[6] C. S. Wu, Y. L. Liu, Y. C. Chiu, Y. S. Chiu, Polym. Degrad. Stab. 2002, 78, 41.

[7] C. S. Wu, Y. L. Liu, Y. S. Chiu, Polymer 2002, 43, 4277.

[8] G. H. Hsiue, Y. L. Liu, J. Tsiao, J. Appl. Polym. Sci. 2000, 78, 1.

[9] W. J. Wang, L. H. Perng, G. H. Hsiue, F. C. Chang, Polymer 2000, $41,6113$.

[10] J. R. Ebdon, B. J. Hunt, M. S. Jones, F. G. Thorpe, Polym. Degrad. Stab. 1996, 54, 395.

[11] G. C. Tesoro, S. B. Sello, J. J. Willard, Text. Res. J. 1968, 38, 245.

[12] G. C. Tesoro, Textilveredlung 1967, 2, 435.

[13] E. J. Gonzales, S. L. Vail, J. Fire Flammability/Fire Retard. Chem. 1974, 1, 142.

[14] J. T. Langley, M. J. Drews, R. H. Barker, J. Appl. Polym. Sci. 1980, 25, 243.

[15] S. K. Brauman, R. Swidler, P. V. Trescony, A. S. Brolly, J. Fire Retard. Chem. 1980, 7, 15.

[16] M. Watanabe, S. Sato, J. Mater. Sci. 1986, 21, 2623.

[17] K. J. Calzia, A. Forcum, A. J. Lesser, J. Appl. Polym. Sci. 2006, 102, 4606.

[18] C. T. Nguyen, J. W. Kim, Polym. Degrad. Stab. 2008, 93, 1037.

[19] M. J. Tsafack, J. Levalois-Grutzmacher, Surf. Coat.Technol. 2006, 201, 2599.

[20] S. Gaan, P. Rupper, V. Salimova, M. J. Heuberger, Anal. Appl. Pyrolysis 2010, 87, 93.

[21] H. L. Lee, G. C. Chen, R. M. Rowell, J. Appl. Polym. Sci. 2004, 91, 2465.

[22] Standard test method for flame resistance of textiles (vertical flame test), American Society for Standards and Testing, ASTM D-6413-08, 2008.

[23] Standard test method for measuring the minimum oxygen concentration..., American Society for Standards and Testing, ASTM D-2863-09, 2009.

[24] N. D. Sachinvala, R. F. Ju, M. H. Litt, W. P. Niemczura, J. Polym. Sci. Pol. Chem. 1995, 33, 15.

[25] Phosphorus NMR, http://chem.ch.huji.ac.il/nmr/techniques/1d/row3/ p.html

[26] T. Ruman, K. Dlugopolska, A. Jurkiewicz, D. Kramarz, T. Fraczyk, A. Les, W. Rode, Lett. Org. Chem. 2009, 6, 642.

[27] L. J. Bellamy, In: The Infra-red Spectra of Complex Molecules, Chapman and Hall, London, 1975, 348-361.

[28] J. W. Kim, C. T. Nguyen, Macromol. Res. 2008, 16, 620.

[29] L. J. Bellamy, In: The Infra-red Spectra of Complex Molecules, Chapman and Hall, London, 1975, 26-27.

[30] L. J. Bellamy, In: The Infra-red Spectra of Complex Molecules, Chapman and Hall, London, 1980, 205.

[31] R. B. Harvey, J. E. Mayhood, Can. J. Chem. 1955, 33(10), 1552.

[32] L. C. Thomas, R. A. Chittenden, Chem. Ind. 1961, 1913.

[33] L. C. Thomas, R. A. Chittenden, Spectrochim. Acta 1966, 22, 1058.

[34] American Association of Textile Chemists and Colorists Technical Manual. 2007, 409.

[35] J. W. Lyons, Chapters 5 and 8, In: The Chemistry and Uses of Fire Retardants 1970.

[36] G. C. Tesoro, S. B. Sello, J. J. Willard, Text. Res. J. 1969, 39, 180. 
[37] W. A. Reeves, Y. B. Marquett, Text. Res. J. 1979, 49, 163.

[38] M. A. Kasem, H. R. Richards, Ind. Eng. Chem. Prod. Res. Develop. 1972, 11(2), 114.

[39] P. Bajaj, Chapter 10, Heat and Flame Protection, In: Handbook of Technical Textiles, (Eds: A. R. Horrocks, S. C. Anand), Woodhead Pub, 2000, 223.

[40] Q. L. Li, X. L. Wang, D. Y. Wang, W. C. Xiong, G. H. Zhong, Y. Z. Wang, J. Appl. Polym. Sci. 2010, 117, 3066.
[41] A. W. Garrison, C. E. Boozer, J. Am. Chem. Soc. 1968, 90, 3486

[42] K. R. Ito, T. lodama, M. Tomizu, Y. Negoro, A. Orita, T. Osaki, N. Hosoki, T. Tanaka, T. Imanishi, S. Obika, Nucleic Acids Res., 2010, 1

[43] A. Mucha, J. Grembecka, T. Cierpicki, P. Kafarski, Eur. J. Org. Chem. 2003, 4797.

[44] J. E. Berger, E. Wittner, J. Phys. Chem. 1966, 70, 1025

[45] S. Gaan, P. Rupper, V. Salimova, M. Heuberger, S. Rabe, F. Vogel, Polym. Degrad. Stab. 2009, 94, 1125. 